\title{
Survey on Home Automation Using Raspberry Pi through GSM
}

\author{
Shrikrushna Khedkar, Dr. G. M. Malwatkr \\ ${ }^{1,2}$ Zeal College of Engineering and Research, Sr.No 39, Off Mumbai-Bangalore Express Highway, Narhe, Pune, India
}

\begin{abstract}
In Resent year Popularity of Home automation has been increasing due to low cost and simplicity through Smartphone and tablet connectivity. It is an automation of home or house hold activity. Raspberry Pi is a small computer, which was introduced in the year of 2012; it is currently a mainstream system subject to extensive availability that can be used in home automation. It is estimated that up to 2020 there will be near about 50 billon internet enable devices available. Home automation may contain centralize controller which control lightning in the house, HAVC( Heating, Ventilation and air conditioning),Security locks of gates, doors and other system to provide improve comfort, connivance security and energy efficiency. The aim of this Paper is to developed an home automation application using RPi and GSM. Programming has been developed in Python environment for RPi operation.
\end{abstract}

Keywords: RPi, GSM, Home Automation, IOT, RESTful.

\section{Introduction}

The first home computer was used for home automation system in 1966. A home automation system nothing but integration of electrical devices in a home. The techniques used in home automation include the building automation as well as the control of domestic activities such as lighting control system, home entertainment systems, yard watering and irrigation system. The popularity of home automation has been increasing greatly in recent years due to low cost and simplicity through Smartphone. The concept here arise i.e. "Internet of Things" has tied in closely with home automation. Internet of Things (IoT) is an going development of the internet by which everyday, things ${ }^{\text {ee }}$ objects have Communication capabilities which allow them to send and receive data [1]. It is estimated that up to 2020 there will be near about 50 billon internet enable devices available.

In home automation systems, devices, sensors which can communicate without the need of machine-to-machine communication.

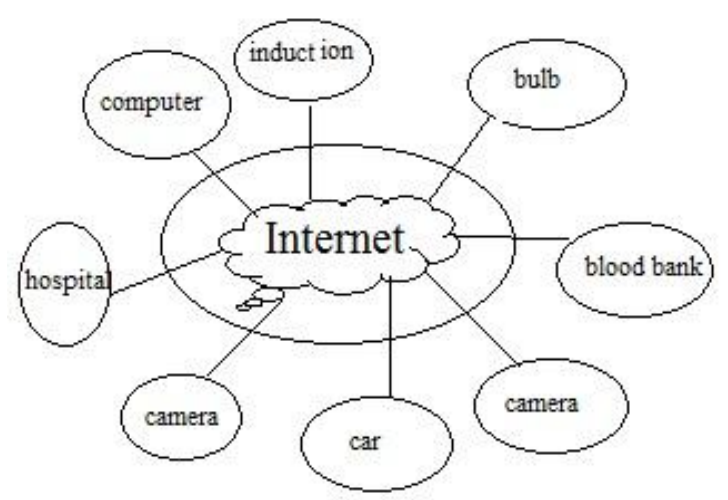

Figure 1: Internet of Thing

There are three way to described home automations:

- Individual control devices,

- Distributed-control systems and

- Centrally controlled systems.
An individual device is device which control only one appliance, examples include; photocell lighting controls and timers, motion detectors, programmable thermostats. A distributed-control system which allows for single appliances to communicate internally with each Other with electrical wiring and without a central controller. A centrally controlled communication in which system transmit signals between a central computer and appliance controllers or environmental sensors [1]. This paper present controlling the home automation appliances using sms services with the help of Raspberry Pi.

Raspberry $\mathrm{Pi}$ is a small computer, which was introduced in the year of 2012, it is currently a mainstream system subject to extensive availability that can be used in home automation. the Raspberry Pi is a series of credit card sized single board computers developed in the UK by the Raspberry $\mathrm{Pi}$ Foundation with the intention of promoting the teaching of basic computer science in schools. As raspberry pi is a small and powerful tool it allows the home automation enthusiast, programmer and electronic hobbyist to enhance their homes with sensors and software. Raspberry Pi is an small computer board which having a large number of input and output peripherals [2]. Raspberry $\mathrm{Pi}$ is not only a processing node in Wireless Sensor Networks (WSN) but also it is act as a controller. 


\section{International Journal of Science and Research (IJSR) \\ ISSN (Online): 2319-7064}

Index Copernicus Value (2013): 6.14 | Impact Factor (2014): 5.611

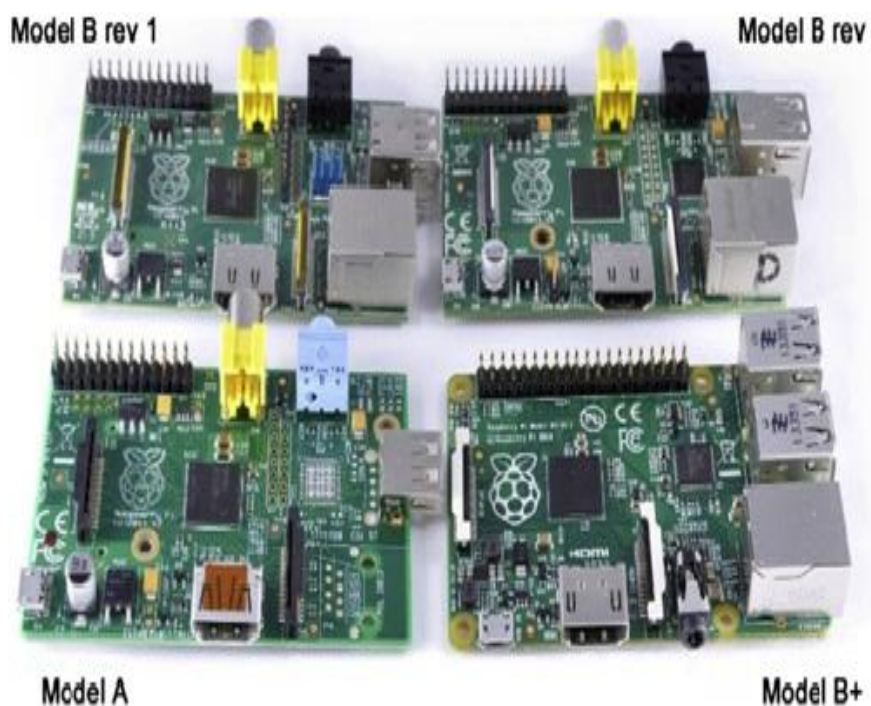

Figure 2: Raspberry Pi Model [1]

The original Raspberry $\mathrm{Pi}$ is based on the Broadcom BCM2835 system on a chip (SoC), It is a small computer with the dimensions $85.60 \mathrm{~mm} \times 53.98 \mathrm{~mm} \times 17 \mathrm{~mm}$, having weight only $45 \mathrm{~g}$ and affordable for $25-35 \$$. The Raspberry Pi contains a processor, program memory (RAM - RandomAccess Memory) and graphics chip also various interfaces and connectors for external devices communication. Raspberry $\mathrm{Pi}$ is low cost, high performance and low power consumption device [2]. The power is provide to Raspberry Pi using alkaline battery. It is made of six rechargeable AA batteries and a voltage regulator. The most suitable pack, which fulfils the relatively high power requirement. Raspberry Pi is nothing but server device which work with whole network of single purpose clients devices. Raspberry Pi having Secure Digital (SD) flash memory which acts as Hard Drive. SD card support up to $32 \mathrm{~GB}, 64 \mathrm{~GB}$ or more than that. Generally $2 \mathrm{~GB}$ is sufficient otherwise it become prohibitively expensive [1]. Devise has USB Mass Storage devices, solid-state drives (SSDs) or pocket-size flash drives. Raspberry Pi Model A has 246 MB of RAM where as B and $\mathrm{B}+$ has $512 \mathrm{MB}$. Ethernet/LAN cable used for Internet Connectivity, In case of Model B has RJ45 Ethernet port, while Model A does not. Model B is auto-sensing in which router or directly to another computer use for connection by creating ad-hoc networks or to connect a wide range of wireless network latest $802.11 \mathrm{n}$ high speed standard will be used [1]. The $3.5 \mathrm{~mm}$ analog audio jack used for connection of headphone and speaker. Raspberry Pi uses Linux Operating System because it is free and open source also Python Programming for activation and deactivation of output load.

Figure 3 Shows the GPIO is General Purpose Input and Output pins on the Raspberry Pi. We have use Raspberry Pi Model in this paper; consist of total 40 pins out of which each row include 20 pins. The first row contains the evennumbered pins, and the other row contains the odd-numbered pins [1]. The GPIO pins can accept input and output commands. They can be accessed for controlling hardware such as LEDs, motors, and relays, which are all examples of outputs. Raspberry Pi can read the status of switches, buttons and dials, or it can read sensors like light, temperature, proximity sensors or motion detector [3].

\begin{tabular}{|c|c|c|c|}
\hline \multicolumn{4}{|c|}{$\begin{array}{l}\text { Raspberry Pi B+ } \\
\text { B+ J8 GPIO Header }\end{array}$} \\
\hline $3.3 \mathrm{~V}$ & 1 & 2 & $5 V$ \\
\hline GPIO2 & 3 & 4 & $5 \mathrm{~V}$ \\
\hline GPIO3 & 5 & 6 & GND \\
\hline GPIO4 & 7 & 8 & GPIO14 \\
\hline GND & 9 & 10 & GPIO15 \\
\hline GPI017 & 11 & 12 & GPIO18 \\
\hline GPIO27 & 13 & 14 & GND \\
\hline GPIO22 & 15 & 16 & GPIO23 \\
\hline $3.3 \mathrm{~V}$ & 17 & 18 & GPIO24 \\
\hline GPIO10 & 19 & 20 & GND \\
\hline GPIO9 & 21 & 22 & GPIO25 \\
\hline GPI011 & 23 & 24 & GPIO8 \\
\hline GND & 25 & 26 & GPIO7 \\
\hline DNC & 27 & 28 & DNC \\
\hline GPIO5 & 29 & 30 & GND \\
\hline GPIO6 & 31 & 32 & GPIO12 \\
\hline GPIO13 & 33 & 34 & GND \\
\hline GPIO19 & 35 & 36 & GPIO16 \\
\hline GPIO26 & 37 & 38 & GPIO20 \\
\hline GND & 39 & 40 & GPIO21 \\
\hline
\end{tabular}

Figure 3: Pin diagram of Raspberry Pi [1]

\section{Literature Survey}

Several definitions are available in the literature survey for home Automation. "Raspberry Pi as a Sensor Web node for Home Automation" This paper proposes an implementation of Sensor Web node as a part of Internet of Things (IOT) using Raspberry Pi (RPi). RPi is customizable, reasonably cost and programmable small computer having large numbers of peripherals and network for communication. Before the IOT technology controlling, monitoring and alerting of devices is not possible. IOT technology provides many advantages including cost saving, security, safety and improve comfort. In this work communication between the remote user and the home devices is implemented using RESTful based Web services. In order to address the issues of flexibility and functionality, a novel, standalone, flexible and low cost home controlling and monitoring system is implemented. Open source software is used for programming which control the devices. Experimental result and performance have shown by Raspberry Pi. Compare with the commercially available home automation systems the proposed system is better from the flexibility and scalability point of view [1]. "Raspberry Pi based Interactive Home Automation System through E-mail" the algorithm developed such a way that it read the subject of E-mail or in other word we can say that, home application controlled through E-mail by reading the subject. The basic application has been implemented and used efficiently. Home Automation implement through web based it consumes more space for web server storage, if it is SMS based then in DTMF call drop is major problem both these disadvantages eliminated through propose method using RPi [2]. "Smart Home System Based on ZigBee and ARM" In this system multiple sensor is monitored by the controller. Short Message is automatically send to the user through system when the value of sensor exceeds the preset threshold value. Manager control the device by sending text message (SMS) to the system. The 


\section{International Journal of Science and Research (IJSR) \\ ISSN (Online): 2319-7064}

Index Copernicus Value (2013): 6.14 | Impact Factor (2014): 5.611

real-time information of system is obtained on displayed. Samsung S3C2440 microprocessor used as a Central controller which used ARM9 control unit. Chipcon's CC2430 ZigBee Network module for wireless connection and GSM module for message transmission and receiving [3]. "Home Automation with a low-cost AVR-based Board" The AVR Processor used ATMega32 as the main controller. Sensor and Home appliance may control remotely via The Internet or Smartphone. Web server is created for communication with the client via REST interface. Four port of AVR processor is A,B,C,D. Out of four 3 port A,C and 6 pin from port D are available for user. Port B connected to Ethernet for In-circuit connection [4]. "Smart GSM Based Home Automation System" Home Automation uses the GSM Modem to control the home appliances. Conditional System, light and security controlled via text message (SMS). PIC16F887 is main microcontroller which controls the home appliances. GSM modem is connected to the PIC16F887 for the communication between user and controller. AT command has been used for GSM communication and Status of devices is obtained on user mobile phone where the device is switch off or on [5].

\section{Existing System}

A home automation system nothing but integration of electrical devices in a home. The techniques used in home automation include the building automation as well as the control of domestic activities such as lighting control system, home entertainment systems, and yard watering and irrigation system. The popularity of home automation has been increasing greatly in recent years due to low cost and simplicity through Smartphone. The concept here arise i.e. "Internet of Things" Internet of Things (IoT) is an going development of the internet by which everyday, things ${ }^{\text {ee }}$ objects have Communication capabilities which allow them to send and receive data.

This paper proposes an implementation of Sensor Web node as a part of Internet of Things (IOT) using Raspberry Pi (RPi). $\mathrm{RPi}$ is customizable, reasonably cost and programmable small computer having large numbers of peripherals and network for communication. In this work communication between the remote user and the home devices is implemented using RESTful based Web services.

\section{Disadvantages of Existing System}

- Home Automation implement through Web based consumes more space for Web server storage.

- Continue Internet connection require for communication between user and system which is costly as compare to available text message services (SMS).

\section{System Architecture}

Propose Architecture of our system shown below in fig no.4 which includes processing unit i.e. Raspberry Pi. This chip is a 32 bit, $700 \mathrm{MHz}$ System on a Chip, which is built on the ARM11 architecture, GSM is the global system for Mobile Communication it is digital mobile telephone system .GSM module can send text message to the required authorities as per the application. GSM is a wireless system with no specified range limit.GSM uses TDMA most widely use of digital wireless technology. It is operated either $900 \mathrm{MHz}$ to $1800 \mathrm{MHz}$ frequency band. GSM modem having bidirectional connection to the RPi used for communication between user and system. RS232 pin used in system. it perform serial communication between the microcontroller and the outside world. The main function is to transfer the data from PC (VB software) to the microcontroller. Relay is the electromagnetic, there is no electrical connection inside the relay the link is mechanical and magnetic. Electromagnetic component act as switch which used to on and off the sensors and home automation devices. It has one normally open terminal, 1 normally closed terminal, a coil and 1 common terminal LCD. ADC is analog to digital convertor use to convert analog input voltage in to the binary coded decimal value. As the processor understand only digital values then it is necessary to convert sense analog value in to the digital and used for further operation.

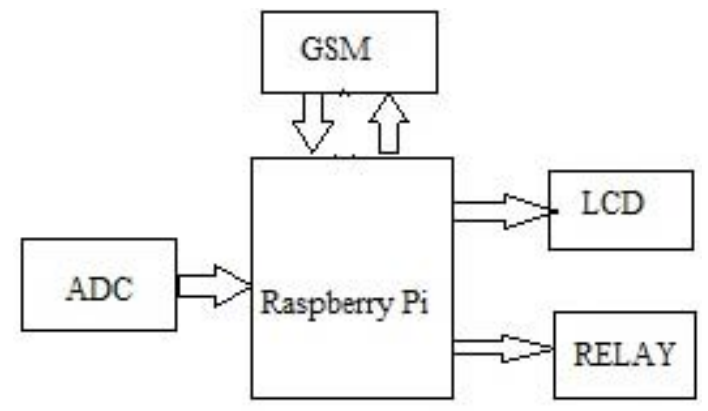

Figure 4: Block diagram of Propose Architecture

\section{Application}

If your lamp could send message to you and suggest replacing the bulb. Furthermore, if your lamp is taking to you, could your sprinkler system and refrigerator too? Expert says yes if you are using home automation. Numerous of application are available base on home automation but some of the them discuss here.

- Lighting Control allows you to control lamps, wall switches. We can customize the timing of lighting for particular room and specific time.

- HVAC Regulation allows to control heating and cooling the room base on schedule time.

- Lawn Irrigation, sprinkler control system are providing water regulation through real time communication with local weather data.

- Smart Appliances such as smart refrigerators allow to scan store grocery and alert you if an item is about to expire.

- Security Systems such as window sensor, motion detectors, video cameras and recording mechanism connected to mobile via cloud to access real time security status of your home.

\section{Conclusion}

In this highly developing era, where directly or indirectly, everything is dependent on computation and information technology, Raspberry Pi proves to be a smart, economic and efficient platform for implementing the home 


\section{International Journal of Science and Research (IJSR) \\ ISSN (Online): 2319-7064}

Index Copernicus Value (2013): 6.14 | Impact Factor (2014): 5.611

automation. In This implementation using Raspberry Pi I have shown the switching operation of electronic devices with the help of relays. The code provided is generic and flexible. Hence this technique is better than other home automation method. In Web server based home automation, the design of web server and space required is eliminated by this method.

\section{Acknowledgement}

I would like to thank the anonymous referees for their helpful guidance that has improved the quality of this paper. Also I would like to thank my Project Guide Dr. G. M. Malwatkar, for his valuable guidance.

\section{References}

[1] Valdimir Vujoic, MirjanaMakshimovic, "Raspberry Pi as a sensor Web node for home automation" Elsevier Transaction on Computer and Engineering 42(2015) 153-171

[2] Sarthak Jain, Anant Vaibhav, Lovely Goyal, “ Raspberry Pi based based Interactive Home Automation System Through Email",IEEE ICROIT Maharaja Agrasen Institute of Techonology Delhi India,Feb 2014

[3] Wu Yi,Wu Tong,Liu Pai,"Smart Home System Based on ZigBee and ARM", The $11^{\text {th }}$ IEEE International Conference On Electronic Measurement and Instrumentation, ICEMI 2013

[4] Jiri Sapale, "Home Automation With Low-Cost AVRBase Board" IFAC (International Federation Of Automatic Control ) Hosting Elsevier,2015

[5] Rozita Teymourzadeh, Salah Addin Ahmed Chan, and Mok VeeHoong, "Smart Base Automation System" IEEE Conference on Systems, Process \& Control,Kuala Lumpur,Malaysia, ICSPC2013

[6] Geza Csemath, Laszelo Szilagyi, “A Novel ECG Telemetry and Monitoring System Based on Z-Wave Communication"30th Annual International IEEE EMBS Conference Vancouver, British Columbia, Canada, August 20-24, 2008

[7] P.S.Joshi, Prof.A.M.Jain, "Wireless Speed Control of an Induction Motor Using Pwm Technique with Gsm", IOSR-JEEE, Volume 6, Issue 2, May-Jun2013

[8] Raspberry $\mathrm{Pi}$ Hardware information, http://elinux.org/RPi_Hardware

[9] Chathura Withanage, Rahul Ashok, Chau Yuen, Kevin Otto , "A Comparison of the Popular Home Automation Technologies" 2014 IEEE Innovative Smart Grid Technologies-Asia (ISGT ASIA)

[10] About Raspberry Pi, http://www.raspberrypi.org/about

[11] Ashi, Home Automation System. Reporter, Vol. 19, no 2,February 2002

[12] Schmidt M. Raspberry Pi-a quick start guide, The Pragmatic Bookshelf; 2013

\section{Author Profile}

Shrikrushna B. Khedkar received his B.E. degree in Electronic and Telecommunication Engineering from Rashtrasant Tukodoji Nagpur University in June 2012. during Feb 2013 to July 2014. He worked as Lecturer at MSPM"s Yashwanrao Chavan Institute Of Polytechnic (YCIP) Beed. Since July 2014, he is working with Navsayhadri Engineering Society Faculty of Engineering (NESFOE) Pune as an Asst. Professor. He has a total 3.1 years of teaching experience.

Dr.G.M.Malwatkar received his B.E. in Instrumentation Engineering from Govt. College of Engineering, Chandrapur, Rashtrasant Tukodoji Nagpur University in the year 2000. He received M.E. in Instrumentation from SGGSIE\&T Nanded. He completed his $\mathrm{PhD}$ in Design of PID controllers for improved performance of higher order Systems in the year 2011. He worked as Development Engineer at Shree Chakradhar Enterprises Pvt. Ltd. for 2.5 year during June 2000 to Dec 2003. He has 9 months of R\&D Experience in IIT Bombay from June 2004 to Feb 2005. He has 13 years of UG and \& 7 years of PG teaching experience. He worked as a lecturer in Dr. Babasaheb Ambedkar Technological University Lonere, Raigad from 23rd July 2001 to 31st may 2002. He worked as a Assistant Professor in Vishwakarma Institute of Technology, Pune, from 14th Feb. 2005 to 8th Feb. 2012. Since $9^{\text {th }}$ Feb 2012, He is working as a Professor at Zeal Education Society"s Zeal (formerly Dnyanganga) College of Engineering \& Research, Pune. 